\title{
Effects of Beclin 1 overexpression on aggressive phenotypes of colon cancer cells
}

\author{
MEI-YING ZHANG ${ }^{1}$, LI-YUAN WANG ${ }^{1}$, SHUANG ZHAO ${ }^{2}$, XIAO-CHONG GUO ${ }^{1}$, \\ YING-QI XU ${ }^{1}$, ZHI-HONG ZHENG ${ }^{1}, \mathrm{HANG}^{2} \mathrm{LU}^{3}$ and HUA-CHUAN ZHENG ${ }^{2}$ \\ ${ }^{1}$ Laboratory Animal Center; ${ }^{2}$ Department of Biochemistry and Molecular Biology, College of Basic Medicine, \\ China Medical University, Shenyang, Liaoning 110001; ${ }^{3}$ Department of Surgery, The First Affiliated Hospital of \\ Liaoning Medical University, Jinzhou, Liaoning 121001, P.R. China
}

Received December 29, 2015; Accepted July 20, 2018

DOI: $10.3892 / \mathrm{ol} .2018 .9817$

\begin{abstract}
Beclin 1 is involved in autophagy, differentiation, apoptosis and cancer progression, and functions as a haploinsufficient tumor suppressor gene. The aim of the present study was to elucidate the function of Beclin 1 in colon cancer. A Beclin 1-expressing plasmid was transfected into HCT-15 and HCT-116 cells, and the phenotypes and associated molecules were determined. Beclin 1 transfectants were subcutaneously injected into nude mice to determine tumor growth, and proliferation and apoptosis levels using Ki-67 immunostaining and terminal deoxynucleotidyl transferase-mediated dUTP nick-end labeling (TUNEL), respectively. Beclin 1 overexpression inhibited viability as determined using a Cell Counting Kit-8 assay, inhibited migration and invasion as determined using a wound healing assay or Transwell assay, and lamellipodia formation by filamentous actin staining, induced autophagy as determined using electron microscopy, and light chain 3B (LC-3B) expression, and apoptosis as determined using Annexin $\mathrm{V}$ staining in the two cell lines $(\mathrm{P}<0.05)$. Beclin 1 induced $\mathrm{G}_{2}$ arrest of HCT-15 transfectants as determined using propidium iodide staining $(\mathrm{P}<0.05)$, whereas HCT-116 transfectants were arrested in $\mathrm{G}_{1}$ phase $(\mathrm{P}<0.05)$. The two transfectants exhibited increased expression of c-Myc, cyclin D1, $\beta$-catenin, insulin-response element 1 and $78 \mathrm{kDa}$ glucose-regulated protein compared with the control and mock cells as determined using the reverse transcription-quantitative polymerase chain reaction $(\mathrm{P}<0.05)$. Beclin 1 overexpression upregulated LC-3B and cyclin-dependent kinase 4 expression, but downregulated cyclin $\mathrm{E}$ expression of the cancer cell lines as determined using western blot analysis $(\mathrm{P}<0.05)$. Beclin 1 expression in vivo significantly suppressed the proliferation of
\end{abstract}

Correspondence to: Professor Hua-Chuan Zheng, Department of Biochemistry and Molecular Biology, College of Basic Medicine, China Medical University, 77 Puhe Road, Shenyang, Liaoning 110001, P.R. China

E-mail: zheng_huachuan@hotmail.com

Key words: colon cancer, Beclin 1, aggressive phenotypes, autophagy, gene therapy colon cancer cells in xenograft models via inducing apoptosis by TUNEL, and inhibiting proliferation by Ki-67 expression $(\mathrm{P}<0.05)$. Beclin 1 overexpression may reverse aggressive phenotypes and suppress colon cancer tumor growth, and be employed as a target molecule for gene therapy of patients with colon cancer.

\section{Introduction}

Beclin 1 participates in the regulation of autophagosome formation and is associated with multiple processes, including tumor suppression, protection against certain cardiac and neurological degenerative diseases, and lifespan extension (1). Beclin 1 possesses B-cell lymphoma 2 homology 3 (BH3) coiled-coil evolutionarily conserved domains from the $\mathrm{N}$ - to the C-terminus (2). Functionally, Beclin 1 is involved in the activation of autophagy and inhibition of proliferation by modulating the formation of Beclin 1-vacuolar protein sorting (Vps)34-Vps15 core complexes (1-4). When Beclin 1 binds to anti-apoptotic proteins [e.g., B-cell lymphoma 2 (Bcl-2), B-cell lymphoma extra-large and Bcl-2-like protein 2], cellular apoptosis may be inhibited and the basal autophagy level may be maintained $(3,4)$. The chemical modification of Beclin 1 , including phosphorylation or ubiquitination by phosphoinositide 3-kinase (PI3K) III or ubiquitin ligases respectively, disrupts the interaction via the $\mathrm{BH} 3$ domain (5). Although Beclin 1 induces autophagy-mediated cell death via caspase-9 (6), caspase-3 and caspase- 8 may cleave Beclin 1 and suppress autophagy in the mitochondrial pathway of apoptosis $(7,8)$.

Beclin 1 is critical for cancer stem-like cell (CSC) maintenance and tumor development in nude mice, whereas its expression limits the development of tumors not enriched with breast CSCs/progenitor cells (9). Biallelic loss of Beclin 1 causes the embryonic mortality of mice, whereas monoallelic loss of Beclin 1 results in an increased tumor risk of lymphoma, and liver and lung cancer $(10,11)$. Previously, it has been identified that Beclin 1 expression is associated with favorable prognosis in stage IIIB colon cancer as an independent factor (12). Park et al (13) identified that Beclin 1 overexpression was independently associated with poorer overall survival of the patients with colon cancer who received 5-fluorouracil-based adjuvant therapy. Koneri et al (14) only 
demonstrated that Beclin 1 overexpression suppressed the cell proliferation and induced $\mathrm{G}_{1}$ arrest of colon cancer cells, with cyclin $\mathrm{E}$ and phosphorylated retinoblastoma levels decreased. In the present study, the effects of Beclin 1 overexpression on cell proliferation, apoptosis, autophagy, invasion, migration and lamellipodia formation of colon cancer cells was analyzed with consideration of the expression of phenotype-associated molecules. Finally, the in vivo effects of Beclin 1 overexpression on tumor growth were determined in nude mice.

\section{Materials and methods}

Cell culture. Colon cancer HCT-15 and HCT-116 cell lines were obtained from by Professor Miyagi Yohei (Clinical Research Institute, Kanagawa Cancer Center, Yokohama, Japan). The cell lines were cultured as monolayers in RPMI-1640 medium (Gibco; Thermo Fisher Scientific, Inc., Waltham, MA, USA) supplemented with $10 \%$ fetal bovine serum (FBS; Gibco; Thermo Fisher Scientific, Inc.), $100 \mathrm{U} / \mathrm{ml}$ penicillin and $100 \mu \mathrm{g} / \mathrm{ml}$ streptomycin at $37^{\circ} \mathrm{C}$ in a humidified atmosphere containing $5 \% \mathrm{CO}_{2}$. All cells were harvested by centrifugation $\left(1,500 \mathrm{x} \mathrm{g}\right.$ for $10 \mathrm{~min}$ at $\left.4^{\circ} \mathrm{C}\right)$ and rinsed with PBS.

Plasmid construction and transfection. Plasmid pT-Beclin 1 was constructed by amplification of Beclin 1 using a DNA amplifier (Thermo Fisher Scientific, Inc.) and a Takara Polymerase kit (Takara Bio, Inc., Otsu, Japan), according to the manufacturer's protocols, with the primers 5'-CTGAGG GATGGAAGGGTCTAAG-3' (sense) and 5'-CCCATTTGT TATAAAATTGTGAGG-3' (antisense). PCR amplification of cDNA was performed in $25 \mu \mathrm{l}$ mixtures containing $0.125 \mu \mathrm{l}$ Pfu (Agilent Technologies, Inc., Santa Clara, CA, USA) with $2.0 \mathrm{mM} \mathrm{MgCl} 2,2.5 \mu 1$ 10X PCR buffer (Takara Bio, Inc.), $2 \mu \mathrm{l}$ dNTP mixture, $1 \mu \mathrm{M}$ of each primer set, and $100 \mathrm{ng}$ template cDNA. PCR conditions were denaturation at $95^{\circ} \mathrm{C}$ for $10 \mathrm{~min}$, followed by 30 cycles of denaturation at $95^{\circ} \mathrm{C}$ for $30 \mathrm{sec}$, annealing at $56^{\circ} \mathrm{C}$ for $30 \mathrm{sec}$ and extension at $72^{\circ} \mathrm{C}$ for $50 \mathrm{sec}$. As a termination step, the extension time of the last cycle was increased to $7 \mathrm{~min}$. The amplicons were purified, digested and inserted into His-tagged pcDNA3.1 (Clontech Laboratories, Inc., Mountainview, CA, USA) between EcoRI and XhoI restriction sites. The HCT-15 and HCT-116 cells were transfected with pcDNA3.1-Beclin 1 or pcDNA3.1 vector following seeding on $6 \mathrm{~cm}$-diameter dishes (NEST, Wuxi, China), and selected by G418 solution with two cell clones obtained.

Proliferation assay. The Cell Counting Kit-8 (CCK-8; Dojindo Molecular Technologies, Inc., Kumamoto, Japan) was used to determine the number of viable cells. Briefly, $2.5 \times 10^{3}$ cells/well were seeded on 96-well plates and allowed to adhere. At various time points $(0,12,24,48,72$ and $96 \mathrm{~h}), 10 \mu \mathrm{l} \mathrm{CCK}-8$ solution was added to each well, the plates were incubated at $37^{\circ} \mathrm{C}$ for $3 \mathrm{~h}$ and the absorbance was determined at $450 \mathrm{~nm}$.

Cell cycle analysis. Cells were digested with $0.25 \%$ trypsin, washed twice with PBS and fixed in $10 \mathrm{ml}$ ice-cold ethanol for $>2 \mathrm{~h}$. Subsequently, cells were washed with PBS and incubated with $100 \mu \mathrm{g} / \mathrm{ml} \mathrm{RNase} \mathrm{A} \mathrm{at} 37^{\circ} \mathrm{C}$ for $1 \mathrm{~h}$. To stain the DNA, propidium iodide (PI) was added to $50 \mu \mathrm{g} / \mathrm{ml}$ prior to incubation at $4^{\circ} \mathrm{C}$ in the dark for $30 \mathrm{~min}$. Finally, flow cytometry was performed to determine the strength of the PI signal using DxFLEX (Beckman Coulter, Inc., Brea, CA, USA) and CytExpert software (Beckman Coulter, Inc.).

Apoptosis assay. Flow cytometry was performed with PI and fluorescein isothiocyanate (FITC)-labeled Annexin V (Nanjing KeyGen Biotech Co., Ltd., Nanjing, China) to detect phosphatidylserine externalization as an endpoint indicator of early apoptosis. A total of $1 \times 10^{6}$ cells was collected and washed with PBS twice. FITC-labeled Annexin V (5 $\mu \mathrm{l})$ and PI $(5 \mu \mathrm{l})$ were added to $490 \mu \mathrm{l} 1 \times 10^{5}$ cell suspension. Following incubation, the cells were analyzed by flow cytometry using DxFLEX and CytExpert software.

Wound healing assay. Cells were seeded at a density of $1.0 \times 10^{6}$ cells/well in 6 -well culture plates. Once confluence was reached, the cell monolayer was scraped with a pipette tip to create a scratch, washed with PBS three times and cultured in the FBS-free RPMI-1640 medium. Images of cells were captured at 24 and $48 \mathrm{~h}$, and the scratch distance was determined using ImageJ bundled with Java 1.8.0_172 (National Institutes of Health, Bethesda, MD, USA).

Cell migration and invasion assay. For the invasion assay, Matrigel-coated chambers (BD Biosciences, Franklin Lakes, NJ, USA) were rehydrated in RPMI-1640 medium for cell seeding. The lower compartment contained 10\% FBS as a chemoattractant. Following culture for $24 \mathrm{~h}$ at $37^{\circ} \mathrm{C}$, cells on the membrane were removed with a cotton bud and the membranes were washed with PBS. Cells migrating through the membrane were fixed in $100 \%$ methanol, stained with Giemsa dye at $37^{\circ} \mathrm{C}$ for $30 \mathrm{~min}$ and quantified under light microscopy at a magnification of $\mathrm{x} 200$. For the migration assay, the procedures were the same except for excluding the control-membrane insert Transwell chamber (BD Biosciences).

Alkaline phosphatase (ALP) activity. ALP activity was employed as a marker of colon cell differentiation. The cells were harvested, broken up and subjected to ALP reagent (Sigma-Aldrich; Merck KGaA, Darmstadt, Germany) at $37^{\circ} \mathrm{C}$ for $2 \mathrm{~h}$. The protein content of the samples was determined using Bio-Rad protein assay kit (Bio-Rad Laboratories, Inc., Hercules, CA, USA), according to the manufacturer's protocol.

Transmission electron microscopy (TEM). Specimens were immersed in $2 \%$ cacodylate-buffered glutaraldehyde. Cells were then rinsed in cacodylate buffer supplemented with $15 \%$ sucrose, post-fixed with $1 \%$ phosphate-buffered $\mathrm{OsO}_{4}$ (pH 7.4), dehydrated with alcohol, clarified in propylene oxide and embedded in Epon using flat molds. Using an ultramicrotome, $1 \mathrm{~nm}$-thick sections were obtained, stained with uranyl acetate, followed by a saturated solution of bismuth subnitrate and finally examined under a Hitachi electron microscope $(\mathrm{x} 1,000,000)$. In each group, sodium butyrate-treated cells (10 $\mathrm{mM}$ for $24 \mathrm{~h}$ ) were used as positive controls.

Immunofluorescence. Cells were seeded on glass coverslips until they had adhered, were fixed with $4 \%$ formaldehyde in PBS for 10 min and permeabilized with $0.2 \%$ Triton X-100 in PBS for $10 \mathrm{~min}$ at room temperature. Following washing with PBS, cells 
were blocked with $1 \%$ bovine serum albumin for $30 \mathrm{~min}$ and subsequently incubated overnight at $4^{\circ} \mathrm{C}$ with goat anti-Beclin 1 (Ab51031; Sigma-Aldrich; Merck KGaA; 1:500) or anti-light chain 3B (LC-3B; wl01506; Cell Signaling Technology, Inc., Danvers, MA, USA; 1:500). Following washing with PBS, the slides were incubated with FITC-conjugated anti-goat immunoglobulin G (IgG; Santa Cruz Biotechnology, Inc., Dallas, TX, USA; sc-2356; 1:1,000) antibody at room temperature for $1 \mathrm{~h}$. To examine lamellipodia formation, the slides were directly incubated overnight at $4^{\circ} \mathrm{C}$ with Alexa Fluor ${ }^{\circledR} 568$ phalloidin (Invitrogen; Thermo Fisher Scientific, Inc.) following washing with PBS 3 times. The cell nuclei were stained with $1 \mu \mathrm{g} / \mathrm{ml}$ DAPI (Sigma-Aldrich; Merck KGaA) for $30 \mathrm{~min}$ at $37^{\circ} \mathrm{C}$. Finally, coverslips were mounted with SlowFade ${ }^{\circledR}$ Gold Antifade reagent (Invitrogen; Thermo Fisher Scientific, Inc.) and observed using a laser-scanning confocal microscope (Olympus Corporation, Tokyo, Japan) at x200 magnification.

Xenograft models. BALB/c nude 8-week male mice $(25 \pm 1.3 \mathrm{~g}$; $\mathrm{n}=20$ ) were maintained under specific pathogen-free conditions with food and water available ad libitum. Mice were housed in plastic cages with paper chips for bedding ( 3 mice/case) in a temperature-controlled room $\left(22-26^{\circ} \mathrm{C}\right)$ with a $12 \mathrm{~h}$ light/dark illumination cycle. Housing and all procedures involving animals were in compliance with the guidelines of the Committee for Animal Experiments of China Medical University (Shenyang, China), who approved the study. In total, 20 mice were arranged into the control and Beclin 1-overexpressing groups, respectively. Subcutaneous xenografts were established by bilateral injection of $1 \times 10^{6}$ cells/mouse. For each tumor, measurements were made using calipers, and the tumor volume calculated as follows: Length $\mathrm{x}$ width ${ }^{2} \mathrm{x} 0.52$. At day 8 post-injection, mice were sacrificed, and part of the tumor was removed, fixed in $10 \%$ formalin at room temperature for 2 days, embedded in paraffin at $65^{\circ} \mathrm{C}$ for $1 \mathrm{~h}$ and cut into $4-\mu \mathrm{m}$-thick sections. The remaining tumors were frozen in liquid nitrogen and stored at $-80^{\circ} \mathrm{C}$.

Reverse transcription-quantitative polymerase chain reaction $(R T-q P C R)$. Total RNA was extracted from colon cancer cell lines using a RNeasy mini kit (Qiagen, Inc., Valencia, CA, USA) and reverse-transcribed into cDNA at $42^{\circ} \mathrm{C}$ for $1 \mathrm{~h}$ using avian myeloblastosis virus reverse transcriptase (Takara Biotechnology Co., Ltd., Tokyo, Japan). Oligonucleotide primers for PCR are presented in Table I. qPCR amplification of cDNA was performed using a $\mathrm{SYBR}^{\circledR}$ Premix Ex Taq ${ }^{\mathrm{TM}}$ II kit (Takara Biotechnology Co., Ltd.), respectively. GAPDH was used as the reference gene. The qPCR conditions were denaturation at $95^{\circ} \mathrm{C}$ for $10 \mathrm{~min}$, followed by 45 cycles of denaturation at $95^{\circ} \mathrm{C}$ for $30 \mathrm{sec}$, annealing at $60^{\circ} \mathrm{C}$ for $30 \mathrm{sec}$ and extension at $55^{\circ} \mathrm{C}$ for $34 \mathrm{sec}$. The gene expression level was expressed as $2^{-\Delta \Delta \mathrm{Cq}}$, where $\Delta \mathrm{Cq}=\mathrm{Cq}$ (gene)-Cq (GAPDH) (15). The expression level in control cells was considered as 1 .

Western blot (WB) analysis. Protein was extracted from colon cancer cells and tissue, and determined using a Bio-Rad assay kit. Denatured protein was separated by SDS/PAGE (10\% acrylamide) and transferred onto a Hybond membrane (GE Healthcare, Chicago, IL, USA), which was blocked overnight in $5 \%$ skimmed milk in Tris-buffered saline with $0.1 \%$ Tween-20 (TBST) at room temperature for $1 \mathrm{~h}$. For immunoblotting, the membrane was incubated with the primary antibody (Table II) at room temperature for $1 \mathrm{~h}$. The membrane was rinsed with TBST and incubated with anti-rabbit (abca2517726), anti-goat (abca2517747) or anti-mouse (orb21692) IgG antibody conjugated to horseradish peroxidase (1:1,000, Dako; Agilent Technologies, Inc.) at room temperature for $1 \mathrm{~h}$. Protein bands were visualized using $\mathrm{X}$ film and Enhanced Chemiluminescence-Plus detection reagents (Santa Cruz Biotechnology, Inc.). The membranes were washed with WB Stripping Solution (Nacalai Tesque, Inc., Kyoto, Japan) and treated as aforementioned.

Immunohistochemistry. Consecutive $4-\mu$ m-thick sections were deparaffinized in xylene twice for $10 \mathrm{~min}$, rehydrate in gradient ethanol $(100,90,80,70$ and $60 \%)$ once for $2 \mathrm{~min}$ at room temperature and subjected to antigen retrieval by irradiation in target retrieval solution (Dako; Agilent Technologies, Inc.) in a microwave oven. The sections were quenched with $3 \% \mathrm{H}_{2} \mathrm{O}_{2}$ to block endogenous peroxidase at room temperature for $15 \mathrm{~min}$. Bovine serum albumin (5\%) was then applied to prevent non-specific binding. The sections were incubated with rabbit anti-beclin 1 (1:100; SAB2103299; Sigma-Aldrich; Merck KGaA) or anti-Ki67 (1:300; Ab15580; Abcam, Cambridge, MA, USA) antibodies, prior to treatment with the horseradish peroxidase-conjugated anti-rabbit secondary antibody as aforementioned (1:100). All incubations were performed in a microwave oven to allow intermittent irradiation. Following each treatment, the slides were washed with TBST three times. Binding sites were visualized with 3,3'-diaminobenzidine. Following counterstaining with Mayer's hematoxylin at room temperature for $2 \mathrm{~min}$, the sections were dehydrated and mounted with coverslips. Omission of the primary antibody was used as a negative control.

Terminal deoxynucleotidyl transferase (TdT) dUTP nick-end labeling (TUNEL). Cell apoptosis was assessed using TUNEL, a method that is based on the specific binding of O-TdT to the 3-OH ends of DNA, ensuring the synthesis of a polydeoxynucleotide polymer. For this purpose, an ApopTag Plus Peroxidase In Situ Apoptosis Detection kit (EMD Millipore, Billerica, MA, USA) was employed according to the manufacturer's protocol. Omission of the working-strength TdT enzyme was used as the negative control.

Statistical analysis. Results are representative of three independent experiments and are expressed as the mean \pm standard deviation. Statistical evaluation was performed using Mann-Whitney U test to differentiate between the means of different groups. $\mathrm{P}<0.05$ was considered to indicate a statistically significant difference. SPSS software (version 10.0; SPSS, Inc., Chicago, IL, USA) was employed to analyze all data.

\section{Results}

Effects of Beclin 1 expression on the phenotypes of colon cancer cell lines and associated molecules. Beclin 1-expressing plasmid was successfully transfected into HCT-15 and HCT-116 cells, as confirmed using RT-qPCR (Fig. 1A), immunofluorescence (Fig. 1B) and western blot analysis using anti-Beclin 1 
Table I. Primer sequences for polymerase chain reaction.

\begin{tabular}{|c|c|c|c|c|}
\hline Gene & Accession number & Primer sequences & Region amplified & Product size, bp \\
\hline Beclin 1 & NM_003766.3 & $\begin{array}{l}\text { F: 5'-GATGGAAGGGTCTAAGACGTCCAA-3' } \\
\text { R: 5'-TTTCGCCTGGGCTGTGGTAAG-3' }\end{array}$ & $162-321$ & 160 \\
\hline c-Myc & X00676 & $\begin{array}{l}\text { F: 5'-AGCGACTCTGAGGAGGAACA-3' } \\
\text { R: 5'-TCCAGCAGAAGGTGATCCA-3' }\end{array}$ & $1,318-1,425$ & 108 \\
\hline Cyclin D1 & NG_000002 & $\begin{array}{l}\text { F: 5'-TGCCACAGATGTGAAGTTCATT-3' } \\
\text { R: 5'-CAGTCCGGGTCACACTTGAT-3' }\end{array}$ & $776-937$ & 162 \\
\hline $\operatorname{Bax}$ & DQ926869 & $\begin{array}{l}\text { F: 5'-GATTGCCGCCGTGGAC-3' } \\
\text { R: 5'-GCCCCAGTTGAAGTTGC-3' }\end{array}$ & $306-393$ & 88 \\
\hline Survivin & DQ508252 & $\begin{array}{l}\text { F: 5'-TTCTCAAGGACCACCGCATC-3' } \\
\text { R: 5'-AGCCTTCCAGCTCCTTGAAG-3' }\end{array}$ & $159-320$ & 162 \\
\hline$\beta$-catenin & X87838 & $\begin{array}{l}\text { F: 5'-GCTTGGAATGAGACTGCTGA-3' } \\
\text { R: 5'-CTGGCCATATCCACCAGAGT-3' }\end{array}$ & $2,221-2,334$ & 114 \\
\hline IRE1 & AF059198 & $\begin{array}{l}\text { F: 5'-ACTGGCTTCTGATAGGAC-3' } \\
\text { R: 5'-GATGTTTGGGTAGATTGTT-3' }\end{array}$ & $1,186-1,272$ & 87 \\
\hline MDR-1 & NM_000927 & $\begin{array}{l}\text { F: 5'-ACACCTGGGCATCGT-3' } \\
\text { R: 5'-TATTAGGCAGTGACTCGA-3' }\end{array}$ & $3,826-3,983$ & 158 \\
\hline GRP78 & FJ436356 & $\begin{array}{l}\text { F: 5'-GTTCTTGCCGTTCAAGGTGG-3' } \\
\text { R: 5'-TGGTACAGTAACAACTGCATG-3' }\end{array}$ & $600-780$ & 181 \\
\hline $\mathrm{p} 21$ & NM_000389.3 & $\begin{array}{l}\text { F: 5'-ACTGTCTTGTACCCTTGTGCC-3' } \\
\text { R: 5'-AAATCTGTCATGCTGGTCTGC-3' }\end{array}$ & $464-571$ & 108 \\
\hline GAPDH & NM_002046.3 & $\begin{array}{l}\text { F: 5'-CAATGACCCCTTCATTGACC-3' } \\
\text { R: 5'-GGAAGATGGTGATGGGATT-3' }\end{array}$ & $201-335$ & 135 \\
\hline
\end{tabular}

F, forward; R, reverse; IRE1, insulin-response element 1; MDR-1, multidrug-resistance gene 1; GRP78, 78 kDa glucose-regulated protein.

Table II. Antibodies used in western blot analysis.

\begin{tabular}{llcll}
\hline Target & Source & Cat. no. & Dilution & \\
\hline His tag & Rabbit & sc-804 & $1: 300$ & Santa Cruz Biotechnology, Inc., Dallas, TX, USA \\
JNK (FL) & Rabbit & sc-571 & $1: 500$ & Santa Cruz Biotechnology, Inc. \\
Bax (B-9) & Mouse & sc-7480 & $1: 300$ & Santa Cruz Biotechnology, Inc. \\
PI3K p110 (D-4) & Mouse & sc-8010 & $1: 300$ & Santa Cruz Biotechnology, Inc. \\
TAK1 (D94D7) & Rabbit & 5206 & $1: 1,000$ & Cell Signaling Technology, Inc., Danvers, MA, USA \\
Cdc25B (H-85) & Rabbit & sc-5619 & $1: 500$ & Santa Cruz Biotechnology, Inc. \\
Cyclin B1 (GNS1) & Mouse & sc-245 & $1: 500$ & Santa Cruz Biotechnology, Inc. \\
CDK4 (C-22) & Rabbit & sc-260 & $1: 500$ & Santa Cruz Biotechnology, Inc. \\
c-Myc (9E10) & Mouse & sc-40 & $1: 300$ & Santa Cruz Biotechnology, Inc. \\
Bcl-2 (C-21) & Rabbit & sc-783 & $1: 500$ & Santa Cruz Biotechnology, Inc. \\
Cyclin E (HE12) & Mouse & sc-247 & $1: 500$ & Santa Cruz Biotechnology, Inc. \\
LC-3B & Rabbit & 2775 & $1: 1,000$ & Cell Signaling Technology, Inc. \\
Beclin 1 & Rabbit & SAB2103299 & $1: 1,000$ & Sigma-Aldrich; Merck KGaA, Darmstadt, Germany \\
$\beta$-actin (C-4) & Mouse & sc-47778 & $1: 2,000$ & Santa Cruz Biotechnology, Inc. \\
\hline
\end{tabular}

JNK, c-Jun N-terminal kinase; FL, full-length; Bax, Bcl-2-associated X protein; PI3K, phosphoinositide 3-kinase; TAK1, transforming growth factor $\beta$-activated kinase 1; CDK4, cyclin-dependent kinase 4; Bcl-2, B-cell lymphoma 2; LC-3B, light chain 3B.

or anti-His tag antibody (Fig. 1C). The transfectants exhibited significantly decreased viability as indicated by CCK-8 staining $(\mathrm{P}<0.05$; Fig. 1D), significantly increased differentiation as observed by ALP activity $(\mathrm{P}<0.05$; Fig. 1E) and markedly increased autophagy as visualized using TEM (Fig. 1F) and LC-3B immunoreactivity (Fig. 1G). The PI staining revealed 
A

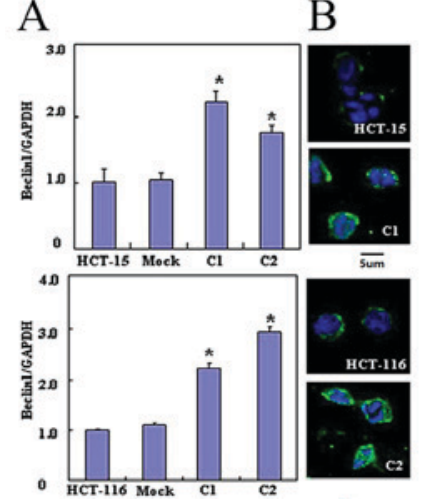

C
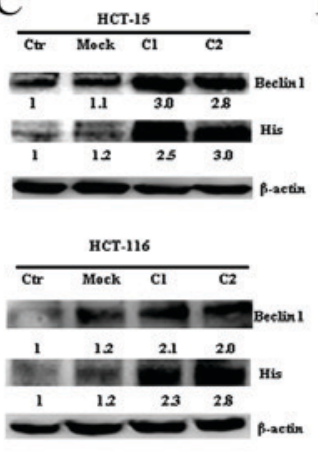

D
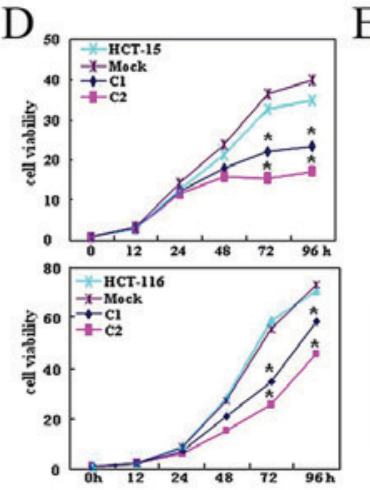

E
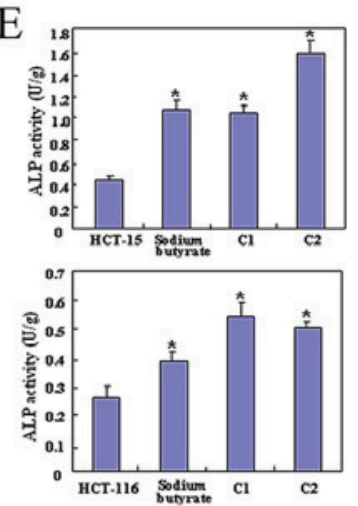
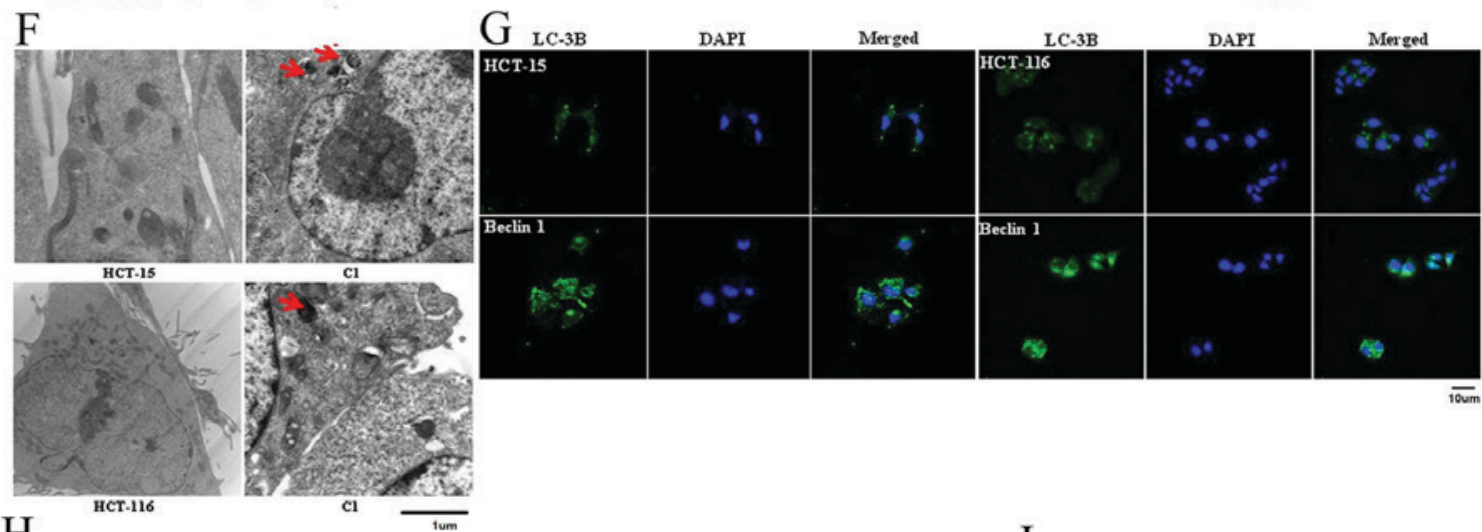

$\mathrm{H}$
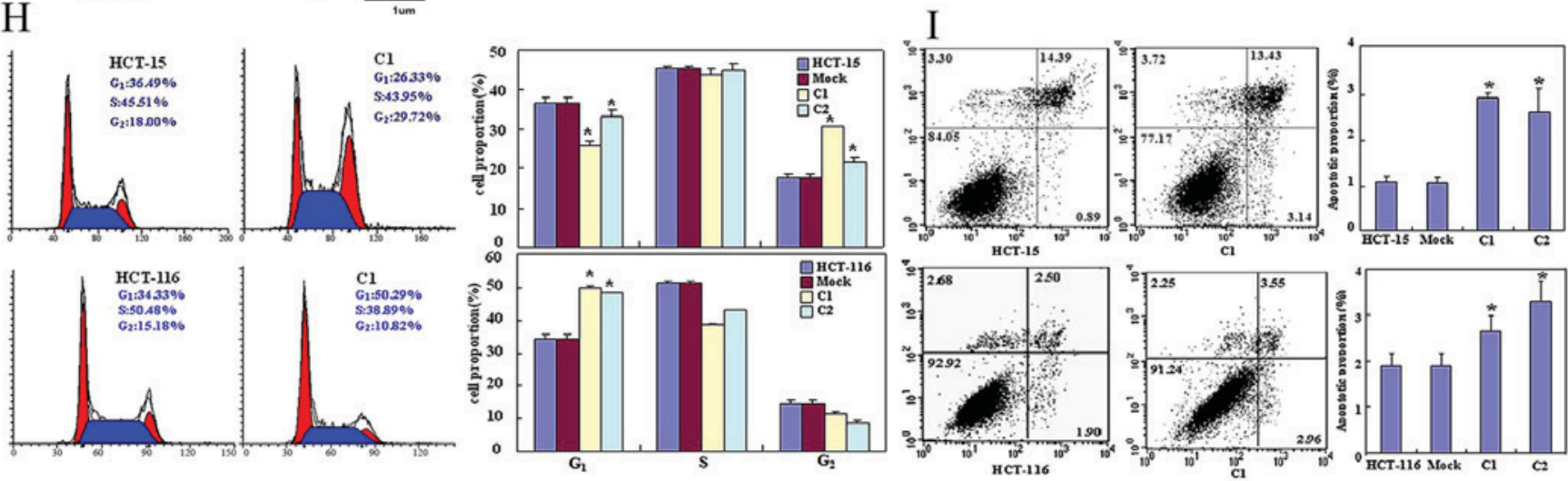

Figure 1. Effects of Beclin 1 expression on proliferation, apoptosis, autophagy and differentiation of HCT-15 and HCT-116 cells. Beclin 1 expression in HCT-15 and HCT-116 cells was determined following transfection with pcDNA3.1-Beclin 1 using (A) reverse transcription-quantitative polymerase chain reaction, (B) immunofluorescence and (C) western blotting. (D) The transfectants exhibited a decrease in viability in comparison with the control and mock. Beclin 1 overexpression may (E) improve the differentiation of HCT-15 and HCT-116 cells as identified by ALP activity and promote autophagy as determined by (F) electron microscopy (red arrow indicates the autophagosome) and (G) marked LC-3B staining. (H) Forced Beclin 1 expression induced the G2 arrest of HCT-15 cells, but the $\mathrm{G}_{1}$ arrest of HCT-116 cells. (I) Apoptosis was increased by Beclin 1 overexpression, as identified using an Annexin V assay. Results are representative of three independent experiments and are expressed as the mean \pm standard deviation. ${ }^{*} \mathrm{P}<0.05$ vs. mock and control groups. ALP, alkaline phosphatase; LC-3B, light chain 3B; Ctr, control; C1, clone 1; C2, clone 2.

that ectopic Beclin 1 overexpression led to significant $\mathrm{G}_{2}$ arrest in HCT-15 cells and $\mathrm{G}_{1}$ arrest in HCT-116 cells $(\mathrm{P}<0.05$; Fig. $1 \mathrm{H})$. Apoptosis observed by Annexin V-FITC staining was increased following Beclin 1 overexpression $(\mathrm{P}<0.05$; Fig. 1I) and lamellipodia formation was weaker as revealed using filamentous actin staining (Fig. 2A) compared with the control and mock cells. Significantly decreased migration and invasion were observed using a wound healing assay $(\mathrm{P}<0.05$; Fig. 2B) or Transwell chamber assay $(\mathrm{P}<0.05$; Fig. $2 \mathrm{C})$ in HCT-15 and HCT-116 transfectants compared with the control and mock cells.

As presented in Fig. 3A, HCT-15 Beclin 1 transfectants exhibited decreased expression of survivin and MDR-1 $(\mathrm{P}<0.05)$, but increased expression of $\mathrm{c}-\mathrm{Myc}$, cyclin $\mathrm{D} 1$,
Bcl-2-associated X protein (Bax), $\beta$-catenin, insulin-response element 1 (IRE1) and GRP78 compared with the control and mock cells by qPCR $(\mathrm{P}<0.05)$. As presented in Fig. 3B, Beclin 1 transfectants of HCT-116 cells exhibited decreased expression of MDR-1 $(\mathrm{P}<0.05)$, but increased expression of c-Myc, p21, cyclin D1, $\beta$-catenin, IRE1 and GRP78 compared with the control and mock cells by qPCR $(\mathrm{P}<0.05)$. At the protein level, Beclin 1 overexpression decreased the expression of cyclin $\mathrm{D} 1$ and $\mathrm{E}(\mathrm{P}<0.05)$, but increased the expression of c-Jun N-terminal kinase (JNK), Bax, PI3K, transforming growth factor $\beta$-activated kinase 1 (TAK1), cyclin-dependent kinase 4 (CDK4), Bcl-2, cyclin B1 and LC-3B in HCT-15 transfectants $(\mathrm{P}<0.05$, Fig. $3 \mathrm{C})$. Beclin 1 overexpression in HCT-116 

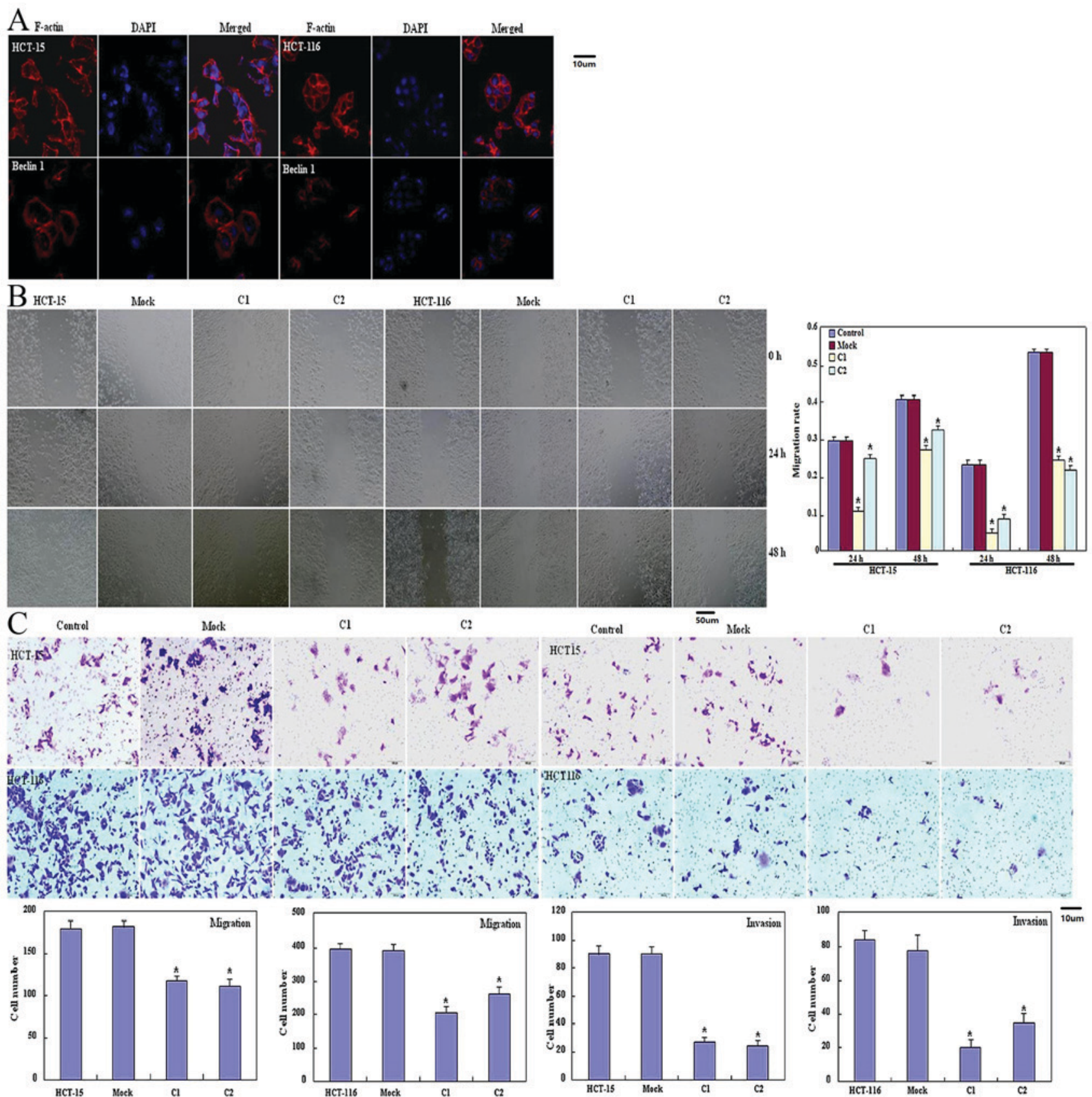

Figure 2. Effects of Beclin 1 expression on lamellipodia formation, migration and invasion of HCT-15 and HCT-116 cells. (A) F-actin immunostaining revealed weaker lamellipodia formation (A) in Beclin-1 HCT-15 and HCT-116 transfectants. Beclin 1 overexpression in HCT-15 and HCT-116 decreased the ability of the cells to migrate and invade as observed in the (B) wound healing assay and (C) Transwell and Matrigel chamber assay. Results are representative of three independent experiments and are expressed as the mean \pm standard deviation. ${ }^{*} \mathrm{P}<0.05$ vs. mock and control groups. F-actin, filamentous actin; $\mathrm{C} 1$, clone 1 ; C2, clone 2 .

transfectants increased the expression of CDK4 and LC-3B $(\mathrm{P}<0.05)$, but decreased the expression of JNK, Bax, PI3K, TAK1, c-Myc, Bcl-2, cyclin B1 and cyclin E (P<0.05; Fig. 3D).

Beclin 1 suppresses the viability of colon cancer cells. As presented in Fig. 4A and B, the tumor volumes of HCT-15 and HCT-116 cells xenografts were increased compared with those of their Beclin 1 transfectants $(\mathrm{P}<0.05)$ although the same number of cancer cells was injected into mice in the two groups. There was significantly increased Beclin $1 \mathrm{mRNA}$ and protein expression in transfectant xenograft tumors of Beclin 1 compared with that of the respective control cells (Fig. 4C;
$\mathrm{P}<0.05)$. Immunohistochemically, Beclin 1 overexpression was observed in Beclin 1 transfectants in comparison with HCT-15 and HCT-116 cells (Fig. 4D). HCT-15 and HCT-116 cells exhibited increased proliferation by the Ki-67 marker compared with their transfectants (Fig. 4D). Increased apoptosis in Beclin 1-overexpressing transfectants was observed compared with the control group using TUNEL (Fig. 4D).

\section{Discussion}

In previous studies, Beclin 1 downregulation was identified to be involved in the carcinogenesis and subsequent progression, 


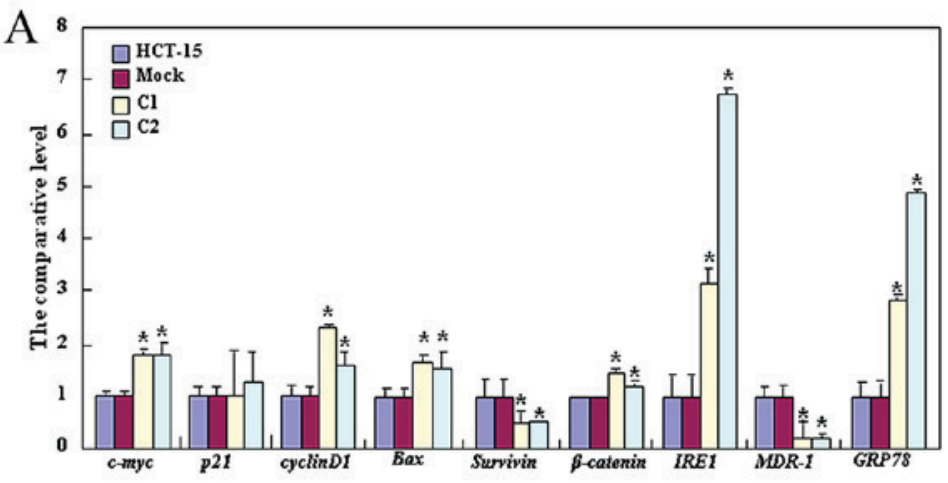

$\mathrm{B}$
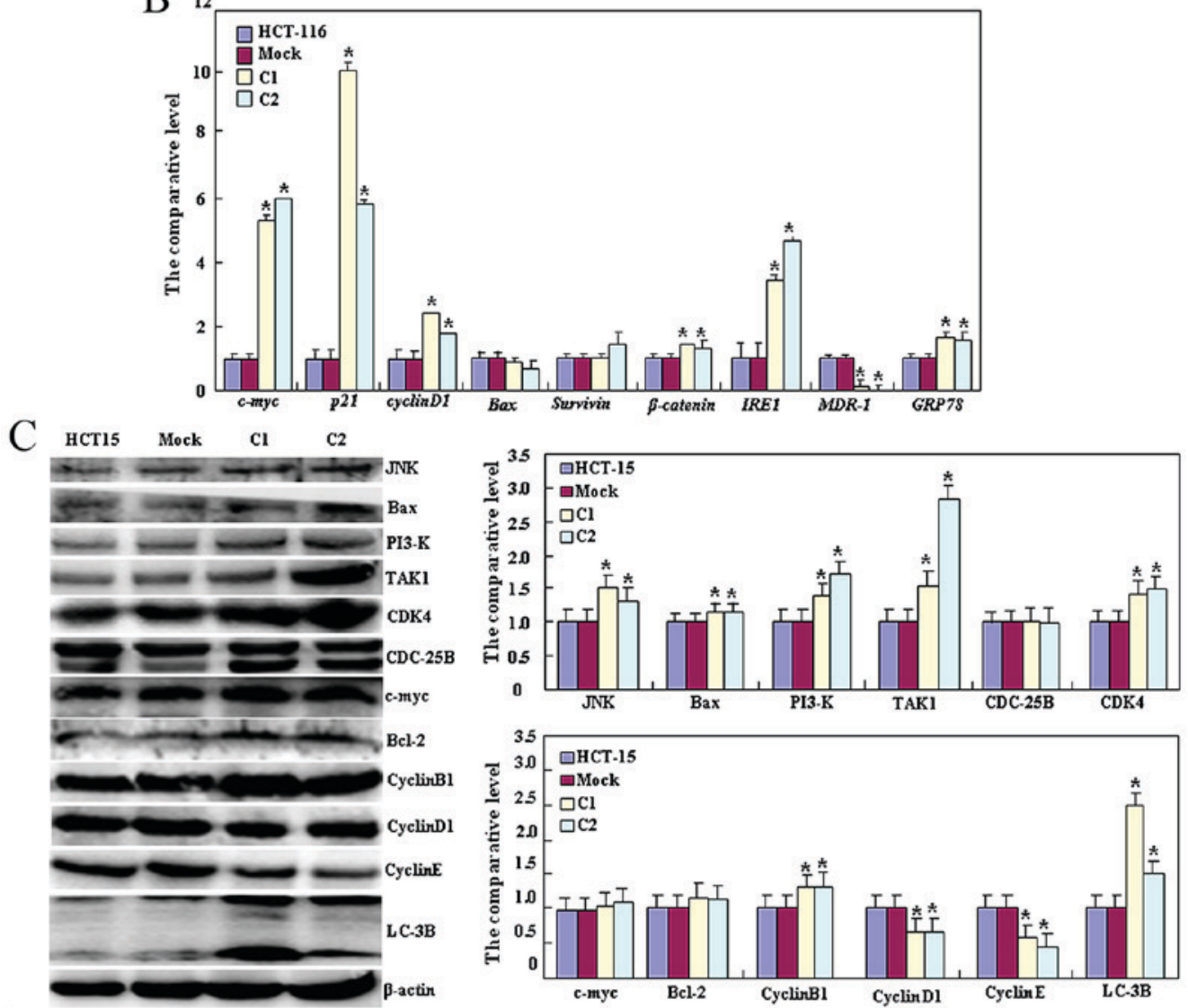

$\mathrm{D}$
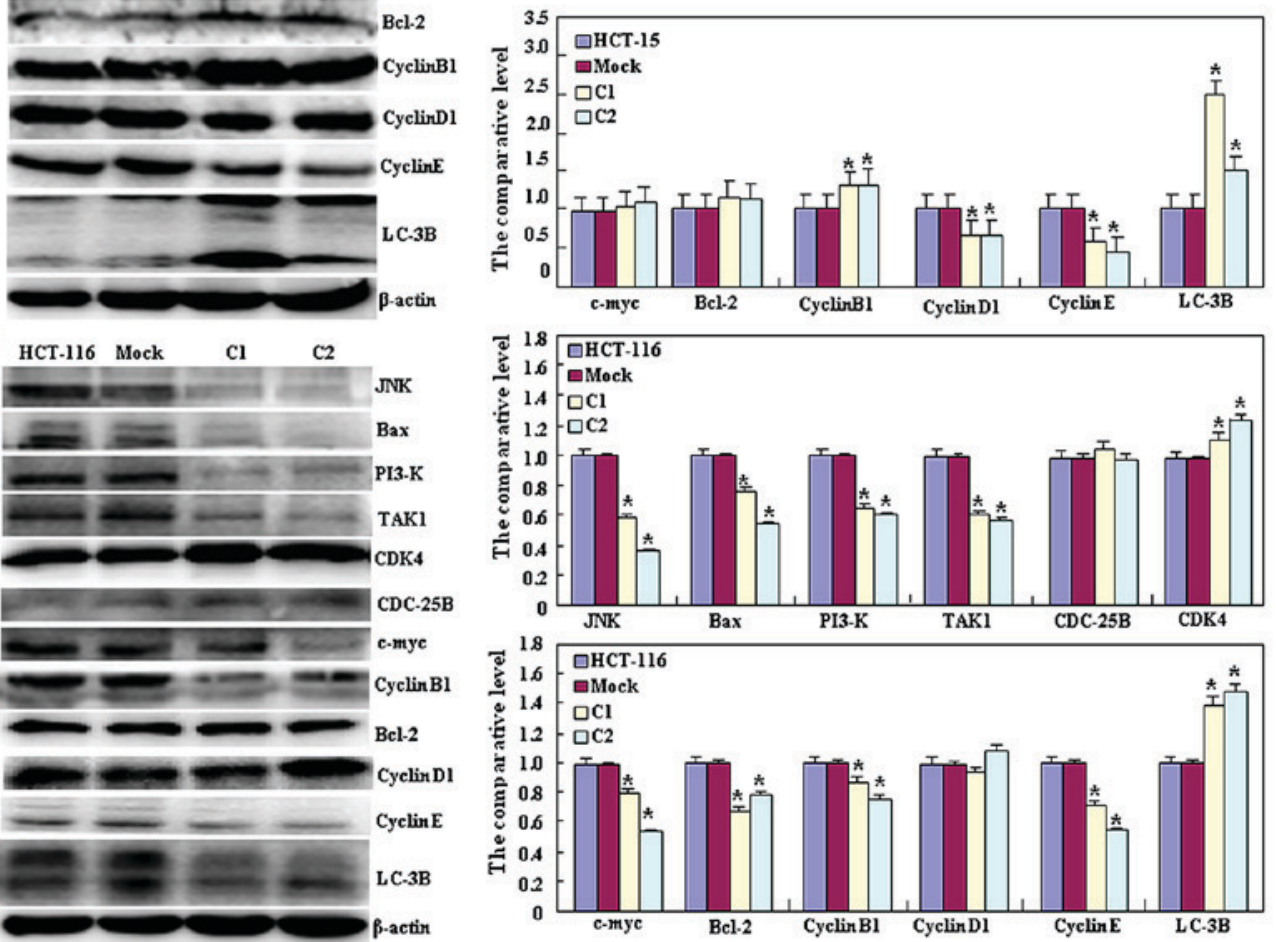

Figure 3. Effects of Beclin 1 expression on phenotype-associated molecules of HCT-15 and HCT-116 cells. Reverse transcription-quantitative polymerase chain reaction analysis of (A) HCT-15 and (B) HCT-116 cells, and western blot analysis of (C) HCT-15 and (D) HCT-116 cells were employed to determine the expression of phenotype-associated molecules in the control, vector mock and Beclin 1 transfectants. Results are representative of three independent experiments and are expressed as the mean \pm standard deviation. ${ }^{*} \mathrm{P}<0.05$ vs. the mock and control groups. JNK, c-Jun N-terminal kinase; Bax, Bcl-2-associated $\mathrm{X}$ protein; TAK1, transforming growth factor $\beta$-activated kinase 1; CDK4, cyclin-dependent kinase 4; Bcl-2, B-cell lymphoma 2; LC-3B, light chain 3B; $\mathrm{C} 1$, clone $1 ; \mathrm{C} 2$, clone 2 . 
$\underline{\mathrm{A}}$

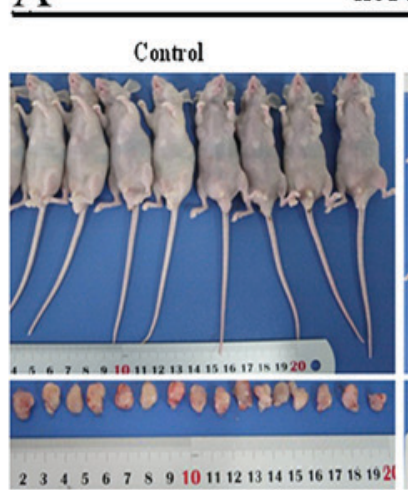

$\mathrm{B}$

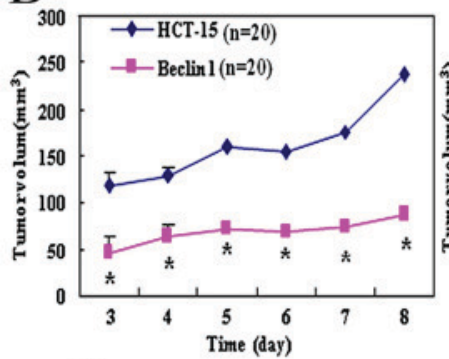

HCT-15
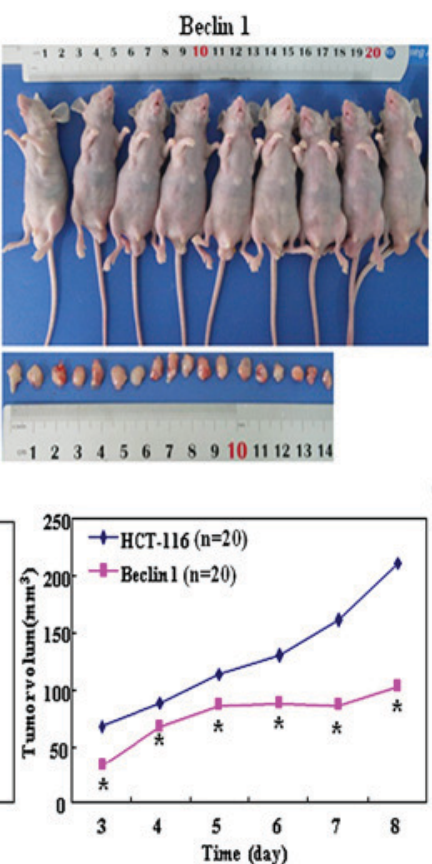

\section{$\dot{\mathrm{C}}$}

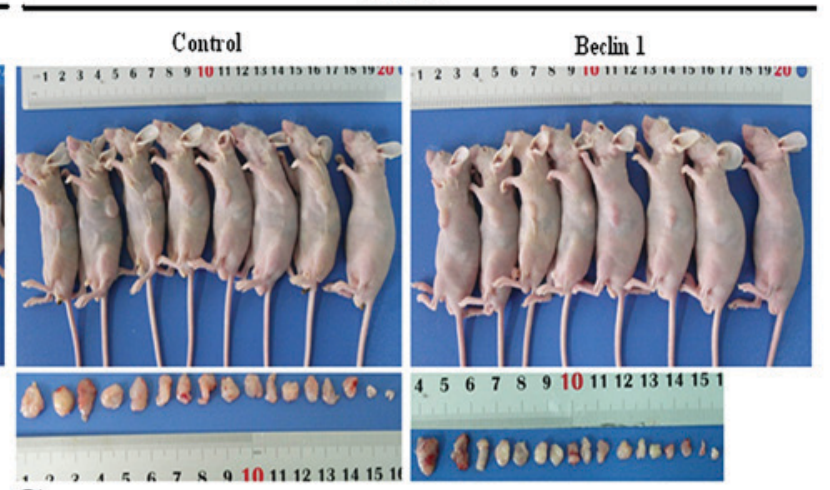

HCT-116

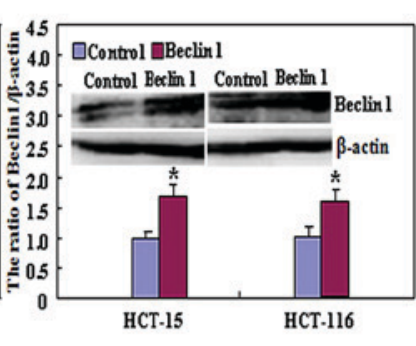

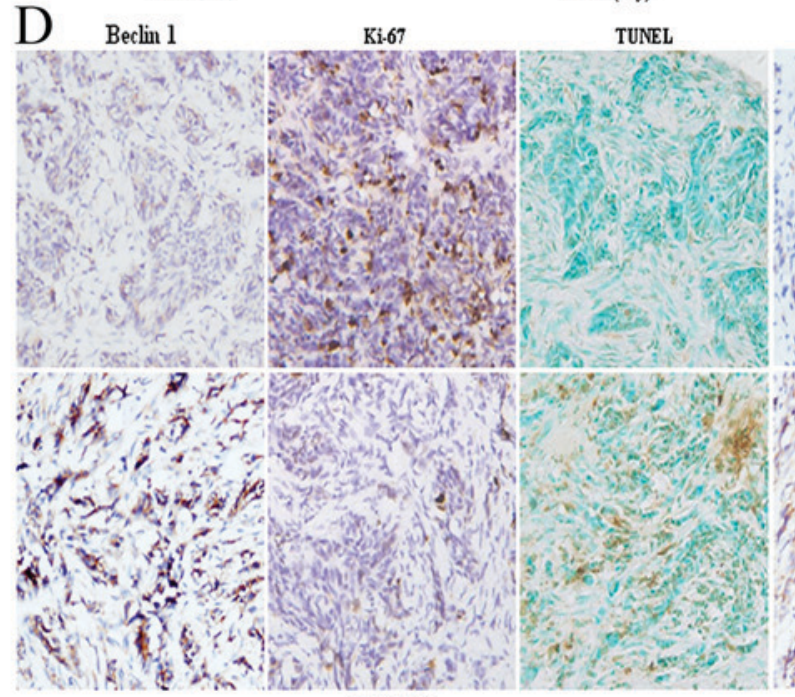

HCT-15

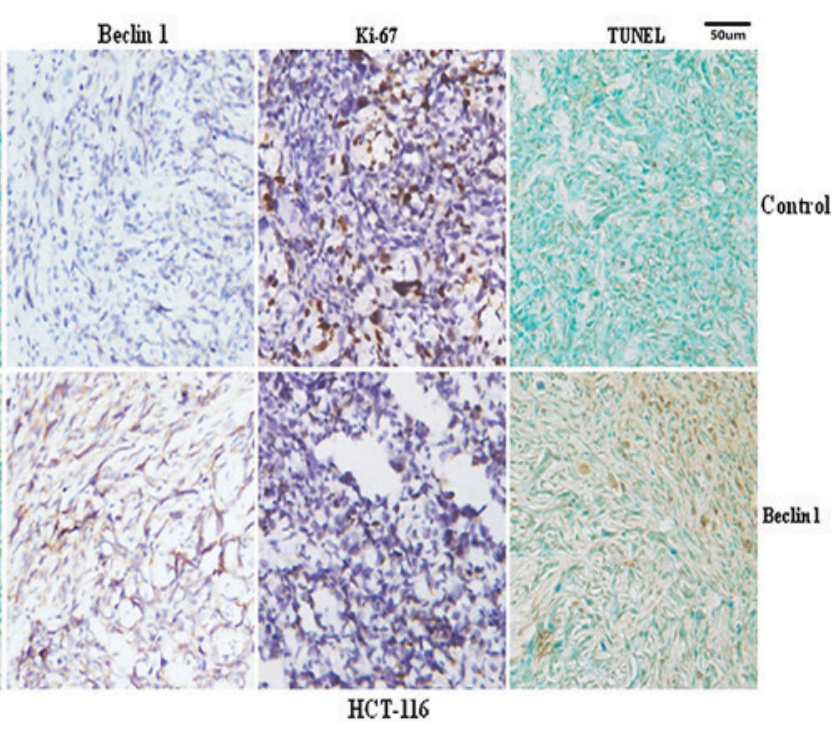

Figure 4. Beclin 1 suppresses the viability of colon cancer cells. (A and B) The proliferation of HCT-15 and HCT-116 cells was increased compared with that of their Beclin 1 transfectant counterparts as revealed by the determination of tumor volumes. (C) Reverse transcription-quantitative polymerase chain reaction and western blot analysis revealed increased Beclin 1 mRNA and protein expression in xenograft tumor of Beclin-1 HCT-15 and HCT-116 transfectants compared with the control cells. (D) Immunohistochemistry identified more marked Beclin 1 expression in the transfectant tumor compared with the control. The transfectant tumor cells also exhibited weaker Ki-67 staining and more marked terminal deoxynucleotidyltransferase-mediated dUTP nick-end labeling staining. Results are expressed as the mean \pm standard deviation. ${ }^{*} \mathrm{P}<0.05$ vs. control.

including invasion and metastasis (16-25). Therefore, we hypothesized that Beclin 1 could be employed as a molecule target for the treatment of cancer, such as in colon cancer. In the present study, the cell function assay revealed that Beclin 1 overexpression may lead to decreased proliferation, cell cycle arrest, increased autophagy and apoptosis in HCT-15 and HCT-116 cells, similar to a previous report (14). In the xenograft model, Beclin 1 overexpression suppressed tumor growth of colon cancer cells by inhibiting proliferation and inducing apoptosis in line with the in vivo data. Pirtoli et al (21) also reported that overexpression of Beclin 1 protein was positively associated with apoptosis, and negatively associated with cell proliferation in high-grade glioma. Additionally, in vitro Beclin 1 overexpression decreased cell migration, invasion and lamellipodia formation of colon cancer cells, indicating that Beclin 1 suppresses invasion and metastasis of colon cancer by inhibiting cellular migration, invasion and mobility. Beclin 1 overexpression also increased differentiation of HCT-15 and HCT-116 cells as revealed by increased ALP activity. Taken together, these results indicate that ectopic Beclin 1 expression may reverse the aggressive phenotypes and have potential for gene therapy for colon cancer. The results of the present study also provide a good explanation for downregulated Beclin 1 expression during carcinogenesis $(18-20,22,24)$ and support 
the inverse correlation of Beclin 1 with aggressiveness and worse prognosis of cancers (16-18,23-25).

It is noteworthy that ectopic Beclin 1 expression resulted in $\mathrm{G}_{2}$ arrest of HCT-15 transfectants and $\mathrm{G}_{1}$ arrest of HCT-116 transfectants, which may be due to differential p21 mRNA expression in the different cell types, as cell cycle $\mathrm{G}_{1}$ arrest results from increased expression of $\mathrm{p} 21^{\text {cip1/waf1 }}$ (26). Cyclin E and D1 activate CDKs, and serve an essential function in the transition between $G_{1}$ and $S$ phase $(27,28)$. Therefore, CDK4 overexpression may account for the $G_{2}$ arrest in HCT-15 transfectants despite the downregulation of cyclin D1 and E expression. In the two cell lines, Beclin 1 overexpression resulted in high levels of MDR-1, IRE1 and GRP78 mRNA, suggesting a function of Beclin 1 in endoplasmic reticulum (ER) stress and drug-resistant suppression as MDR-1, GRP78 and IRE1 have been identified to be involved in protein folding of ER and decreased drug accumulation $(29,30)$. The effect of Beclin 1 on the transcription of c-Myc, cyclin D1 and $\beta$-catenin requires further investigation. Bcl-2 interacts with Bax on the mitochondrial membrane to suppress apoptosis as Bax is hypothesized to open the mitochondrial voltage-dependent anion channel for apoptosis (31). Consequently, Bax overexpression in HCT-15 cells and Bcl-2 hypoexpression in HCT-116 cells may explain the induction of apoptosis by Beclin 1 in the two cell lines. It has been reported that TAK1 phosphorylates mitogen-activated protein kinase kinase 4 and 3/6, which activate JNK (32). The upregulated expression of TAK1 and JNK in HCT-116 transfectants indicated that Beclin 1 may strengthen this signal pathway.

In summary, Beclin 1 overexpression suppresses proliferation, migration and invasion, yet induces apoptosis, autophagy and differentiation of colon cancer cells. Therefore, Beclin 1 is a potential candidate for the future target gene therapy for colon cancer.

\section{Acknowledgements}

Not applicable.

\section{Funding}

The present study was supported by A Project Supported by Scientific Research Fund of Liaoning Provincial Education Department (grant nos. LJQ2014093 and L2014333), Liaoning BaiQianWan Talents Program, Outstanding Scientific Fund of Shengjing Hospital, Award for Liaoning Distinguished Professors, Shenyang Science and Technology Grand (grant no. 18-013-0-59) and the National Natural Scientific Foundation of China (grant nos. 81472544 and 81672700).

\section{Availability of data and materials}

The datasets used and/or analyzed during the current study are available from the corresponding author on reasonable request.

\section{Authors' contributions}

MYZ, LYW, SZ, XCG, HL and YQX conducted the experiments and analyzed the data. HCZ and $\mathrm{ZHZ}$ designed the study and wrote the manuscript.

\section{Ethics approval and consent to participate}

The animal experiments were approved by the Committee for Animal Experiments of China Medical University (Shenyang, China).

\section{Patient consent for publication}

Not applicable.

\section{Competing interests}

The authors declare that they have no competing interests.

\section{References}

1. Liang XH, Jackson S, Seaman M, Brown K, Kempkes B, Hibshoosh $\mathrm{H}$ and Levine B: Induction of autophagy and inhibition of tumorigenesis by Beclin 1. Nature 402: 672-676, 1999.

2. Liang XH, Yu J, Brown K and Levine B: Beclin 1 contains a leucine-rich nuclear export signal that is required for its autophagy and tumor suppressor function. Cancer Res 61: 3443-3449, 2001.

3. Kang R, Livesey KM, Zeh HJ, Loze MT and Tang D: HMGB1: A novel Beclin 1-binding protein active in autophagy. Autophagy 6: 1209-1211, 2010.

4. Kang R, Zeh HJ, Lotze MT and Tang D: The Beclin 1 network regulates autophagy and apoptosis. Cell Death Differ 18: 571-580, 2011.

5. Abrahamsen H, Stenmark H and Platta HW: Ubiquitination and phosphorylation of Beclin 1 and its binding partners: Tuning class III phosphatidylinositol 3-kinase activity and tumor suppression. FEBS Lett 586: 1584-1591, 2012.

6. Wang ZH, Xu L, Duan ZL, Zeng LQ, Yan NH and Peng ZL: Beclin 1-mediated macroautophagy involves regulation of caspase-9 expression in cervical cancer HeLa cells. Gynecol Oncol 107: 107-113, 2007.

7. Li H, Wang P, Sun Q, Ding WX, Yin XM, Sobol RW, Stolz DB, Yu J and Zhang L: Following cytochrome c release, autophagy is inhibited during chemotherapy-induced apoptosis by caspase 8-mediated cleavage of Beclin 1. Cancer Res 71: 3625-3634, 2011

8. Zhu Y, Zhao L, Liu L, Gao P, Tian W, Wang X, Jin H, Xu H and Chen Q: Beclin 1 cleavage by caspase-3 inactivates autophagy and promotes apoptosis. Protein Cell 1: 468-477, 2010.

9. Gong C, Bauvy C, Tonelli G, Yue W, Deloménie C, Nicolas V, Zhu Y, Domergue V, Marin-Esteban V, Tharinger $\mathrm{H}$, et al: Beclin 1 and autophagy are required for the tumorigenicity of breast cancer stem-like/progenitor cells. Oncogene 32: 2261-2272, 2013.

10. Qu X, Yu J, Bhagat G, Furuya N, Hibshoosh H, Troxel A, Rosen J, Eskelinen EL, Mizushima N, Ohsumi Y, et al: Promotion of tumorigenesis by heterozygous disruption of the Beclin 1 autophagy gene. J Clin Invest 112: 1809-1820, 2003.

11. Yue Z, Jin S, Yang C, Levine AJ and Heintz N: Beclin 1, an autophagy gene essential for early embryonic development, is a haploinsufficient tumor suppressor. Proc Natl Acad Sci USA 100: 15077-15082, 2003.

12. Li BX, Li CY, Peng RQ, Wu XJ, Wang HY, Wan DS, Zhu XF and Zhang XS: The expression of beclin 1 is associated with favorable prognosis in stage IIIB colon cancers. Autophagy 5: 303-306, 2009.

13. Park JM, Huang S, Wu TT, Foster NR and Sinicrope FA: Prognostic impact of Beclin 1, p62/sequestosome 1 and LC3 protein expression in colon carcinomas from patients receiving 5-fluorouracil as adjuvant chemotherapy. Cancer Biol Ther 14: 100-107, 2013.

14. Koneri K, Goi T, Hirono Y, Katayama K and Yamaguchi A: Beclin 1 gene inhibits tumor growth in colon cancer cell lines. Anticancer Res 27: 1453-1457, 2007.

15. Livak KJ and Schmittgen TD: Analysis of relative gene expression data using real-time quantitative PCR and the 2(-Delta Delta C(T)) method. Methods 25: 402-408, 2001.

16. Chen Y, Lu Y, Lu C and Zhang L: Beclin-1 expression is a predictor of clinical outcome in patients with esophageal squamous cell carcinoma and correlated to hypoxia-inducible factor (HIF)-1alpha expression. Pathol Oncol Res 15: 487-493, 2009. 
17. Dong LW, Hou YJ, Tan YX, Tang L, Pan YF, Wang M and Wang HY: Prognostic significance of Beclin 1 in intrahepatic cholangiocellular carcinoma. Autophagy 7: 1222-1229, 2011.

18. Duan ZL, Peng ZL and Wang ZH: Expression and involved signal transduction pathway of autophagy gene Beclin lin epithelial ovarian cancer. Sichuan Da Xue Xue Bao Yi Xue Ban 38 239-242, 2007 (In Chinese).

19. Huang X, Bai HM, Chen L, Li B and Lu YC: Reduced expression of LC3B-II and Beclin 1 in glioblastoma multiforme indicates a down-regulated autophagic capacity that relates to the progression of astrocytic tumors. J Clin Neurosci 17: 1515-1519, 2010.

20. Jiang ZF, Shao LJ, Wang WM, Yan XB and Liu RY: Decreased expression of Beclin-1 and LC3 in human lung cancer. Mol Biol Rep 39: 259-267, 2012.

21. Pirtoli L, Cevenini G, Tini P, Vannini M, Oliveri G, Marsili S, Mourmouras V, Rubino G and Miracco C: The prognostic role of Beclin 1 protein expression in high-grade gliomas. Autophagy 5: 930-936, 2009.

22. Shi YH, Ding ZB, Zhou J, Qiu SJ and Fan J: Prognostic significance of Beclin 1-dependent apoptotic activity in hepatocellular carcinoma. Autophagy 5: 380-382, 2009.

23. Wan XB, Fan XJ, Chen MY, Xiang J, Huang PY, Guo L, Wu XY, $\mathrm{Xu} \mathrm{J}$, Long ZJ, Zhao Y, et al: Elevated Beclin 1 expression is correlated with HIF-1alpha in predicting poor prognosis of nasopharyngeal carcinoma. Autophagy 6: 395-404, 2010.

24. Wang ZH, Peng ZL, Duan ZL and Liu H: Expression and clinical significance of autophagy gene Beclin 1 in cervical squamous cell carcinoma. Sichuan Da Xue Xue Bao Yi Xue Ban 37: 860-863, 2006 (In Chinese).
25. Won KY, Kim GY, Lim SJ and Kim YW: Decreased Beclin-1 expression is correlated with the growth of the primary tumor in patients with squamous cell carcinoma and adenocarcinoma of the lung. Hum Pathol 43: 62-68, 2012.

26. Pajalunga D, Mazzola A, Franchitto A, Puggioni E and Crescenzi M: The logic and regulation of cell cycle exit and reentry. Cell Mol Life Sci 65: 8-15, 2008.

27. Müller GA and Engeland K: The central role of CDE/CHR promoter elements in the regulation of cell cycle-dependent gene transcription. FEBS J 277: 877-893, 2010.

28. Wang C, Lisanti MP and Liao DJ: Reviewing once more the c-myc and Ras collaboration: Converging at the cyclin D1-CDK4 complex and challenging basic concepts of cancer biology. Cell Cycle 10: 57-67, 2011

29. Wang LH, Song YB, Zheng WL, Jiang L and Ma WL: The association between polymorphisms in the MDR1 gene and risk of cancer: A systematic review and pooled analysis of 52 case-control studies. Cancer Cell Int 13: 46, 2013.

30. Zheng HC, Takahashi H, Li XH, Hara T, Masuda S, Guan YF and Takano Y: Overexpression of GRP78 and GRP94 are markers for aggressive behavior and poor prognosis in gastric carcinomas. Hum Pathol 39: 1042-1049, 2008.

31. Adams JM and Cory S: The Bcl-2 apoptotic switch in cancer development and therapy. Oncogene 26: 1324-1337, 2007.

32. Ninomiya-Tsuji J, Kishimoto K, Hiyama A, Inoue J, Cao Z and Matsumoto K: The kinase TAK1 can activate the NIK-I kappaB as well as the MAP kinase cascade in the IL-1 signaling pathway. Nature 398: 252-256, 1999. 